\title{
Detection of Beijing strains of MDR $M$. tuberculosis and their association with drug resistance mutations in katG, rpoB, and embB genes
}

Anamika Gupta ${ }^{1,2}$, Pallavi Sinha', Vijay Nema², Pramod K. Gupta ${ }^{3}$, Pampi Chakraborty³, Savita Kulkarni Nalin Rastogi ${ }^{4}$ and Shampa Anupurba ${ }^{1 *}$ (i)

\begin{abstract}
Background: Molecular epidemiological studies of Mycobacterium tuberculosis (MTB) are the core of current research to find out the association of the $M$. tuberculosis genotypes with its outbreak and transmission. The high prevalence of the Beijing genotype strain among multidrug resistance (MDR) TB has already been reported in various studies around India. The overall objective of this study was to detect the prevalence of Beijing genotype strains of MDR M. tuberculosis and their association with the clinical characteristics of TB patients.

Methods: In this study 381 M. tuberculosis clinical isolates were obtained from sputum samples from 2008 to 2014. The multiplex-PCR and Spoligotyping $(n=131)$ methods were used to investigate the prevalence of the Beijing genotype strain by targeting the Rv2820 gene and their association with drug resistance and clinical characteristics of TB patients. The drug susceptibility testing of first-line anti-TB drugs was performed by using the proportion method and MGIT960. A collection of isolates having Beijing and non-Beijing strains were also characterized to see if Beijing genotype strains had a higher rate of mutations at codons 516, 526 and 531 of the 81-bp region of the rpoB gene, codon 315 of the kat $G$ gene, and codon 306 of the embB gene.

Results: The sensitivities and specificities of multiplex-PCR assay compared to that of standard Spoligotyping was detected to be $100 \%$. Further, we observe that the multi drug-resistance was significantly associated with Beijing genotype strains $(p=0.03)$ and a strong correlation between Beijing genotype strains and specific resistance mutations at the katG315, rpoB531, and embB306 codons ( $p=<0.0001,<0.0001 \& 0.0014$ respectively) was also found.

Conclusions: This rapid, simple, and cost-effective multiplex PCR assay can effectively be used for monitoring the prevalence of Beijing genotype strains in low resource settings. Findings of this study may provide a scientific basis for the development of new diagnostic tools for detection and effective management of DR-TB in countries with a higher incidence rate of Beijing genotype strains.
\end{abstract}

Keywords: Beijing genotype, Rv2820, Spoligotyping, Drug resistant-TB, Transmission, Tuberculosis

\footnotetext{
* Correspondence: shampa_anupurba@yahoo.co.in

${ }^{1}$ Department of Microbiology, Institute of Medical Sciences, Banaras Hindu University, Varanasi 221 005, India

Full list of author information is available at the end of the article
}

(c) The Author(s). 2020 Open Access This article is licensed under a Creative Commons Attribution 4.0 International License, which permits use, sharing, adaptation, distribution and reproduction in any medium or format, as long as you give appropriate credit to the original author(s) and the source, provide a link to the Creative Commons licence, and indicate if changes were made. The images or other third party material in this article are included in the article's Creative Commons licence, unless indicated otherwise in a credit line to the material. If material is not included in the article's Creative Commons licence and your intended use is not permitted by statutory regulation or exceeds the permitted use, you will need to obtain permission directly from the copyright holder. To view a copy of this licence, visit http://creativecommons.org/licenses/by/4.0/ The Creative Commons Public Domain Dedication waiver (http://creativecommons.org/publicdomain/zero/1.0/) applies to the data made available in this article, unless otherwise stated in a credit line to the data. 


\section{Background}

Beijing genotype of $M$. tuberculosis (MTB) strain attracted expert's attention due to its association with multidrug resistance (MDR) and disease outbreaks [1]. Justifications for the rapid dissemination of Beijing genotype strain have included its putative elevated virulence, enhanced transmissibility, greater mutability, ability to escape from BCG vaccine-induced immunity, and its skill to acquire multidrug resistance [2-5]. Information about the transmission of Beijing-genotype MTB strain circulating in North India is lacking. Therefore, as a part of our overall objective we have attempted to assess the prevalence of Beijing genotype MTB strain and its relation to drug resistance and clinical characteristics of TB patients in North India.

An extensive review of the mechanism behind successful emergence of the Beijing genotype strain has revealed a higher frequency of mutation at the codon 315 of kat $G$ gene among MTB Beijing genotype strains [6]. However, the association is less clear for mutations at codons 516, 526 , and 531 of the rpoB gene, and at the codon 306 of the $e m b B$ gene [5]. We characterized a collection of MTB patient isolates to see if the Beijing genotype strain had a higher rate of mutations at the katG315 codon, the rpoB516, rpoB526, and rpoB531 codons of RRDR region which accounts for $>95 \%$ of resistance to rifampicin (RIF), and embB306, which is responsible for resistance to ethambutol (EMB) [7, 8]. Further, we also have evaluated a multiplex PCR against standard spoligotyping for the rapid and cost-effective detection of Beijing genotypes of MTB strains.

\section{Methods}

\section{Setting}

Banaras Hindu University (BHU) hospital is a tertiarycare hospital with vast catchment area, being the only tertiary care hospital in Eastern Uttar Pradesh (UP), situated in North Central India, providing medical cover to over 200 million population of Eastern UP, Western Bihar and adjoining areas of Madhya Pradesh. It's a tertiary care center with a referral bias towards nonresponding cases.

\section{Study subjects}

TB patients, age range 6-90 years, with or without any other additional complications such as HIVseropositivity, have been included in this study. Other details were received from the medical files and compliance charts. Treatment of TB patients was done according to the standard short-course chemotherapy under DOTS guidelines [9]. The written informed consent was obtained from all participants.

\section{Collection of samples}

Four thousand seventy nine sputum specimens were collected during 2008-2014, from the patients of pulmonary tuberculosis, from three $\mathrm{TB}$ - centers and analyzed for culture positivity to Mycobacterium tuberculosis.

\section{Mycobacterial isolates}

A total of 381 MTB isolates were isolated from 4079 TB suspected specimens collected over 6 years (2008 to 2014) from TB patients attending different health care centers and BHU hospital of Varanasi, UP, India.

\section{Drug susceptibility testing}

A total of 381 MTB isolates were subjected to DST according to the standard proportion method (PM) and commercial MGIT960 system against RIF, INH, streptomycin (STR), and EMB [10]. H37Rv (ATCC 27294) and known RIF, INH, and EMB monoresistant strains were used as negative and positive controls respectively.

\section{HIV testing}

Three rapid HIV test kits based on different antigens/ principles were used according to NACO (National AIDS Control Organization) guidelines for the detection of HIV in patients with TB [11].

\section{Multiplex-allele specific-PCR (MAS-PCR)/DNA sequencing for detection of RIF, INH and EMB resistance determinants} DNA was isolated as described by van Embden et al and a two-step MAS-PCR assay was performed to detect mutations at rpoB codons $(516,526$, and 531), $k a t G$ codon 315 and $e m b B$ codon 306 [12-14]. Automated sequencing was performed using the BigDye Terminator kit v3.1 (Applied Biosystems, USA) as per manufacturer's protocol. DNA sequence analysis was carried out for 61 strains. Further comparisons of $\operatorname{rpoB}(n=128)$, katG $(n=128)$ and embB306 $(n=27)$ were carried out with SeqScape ${ }^{\bullet}$ v2.5 software.

\section{Spoligotyping}

Out of 381 MTB isolates, spoligotyping was performed for 131 isolates according to the standard method of Kamerbeek et al. [15]. The spoligotypes were compared with those contained in the international database SITVIT2, an updated variant of the previously released SpolDB4 database [16]. Isolates of the Beijing genotype were defined by showing hybridization to at least three of the nine spacers within $35-43$ and showing the absence of hybridization to spacers 1 to 34. Some Beijing strains lack one or more of the nine 
signature spacers, due to asymmetrical insertions of IS6110 (Table 3).

\section{Multiplex-PCR for the identification of Beijing genotypes of MTB targeting Rv2820 gene}

To differentiate between Beijing and non-Beijing strains of 381 MTB isolate, three sets of PCR primers were used (Supplementary Table $1[17,18]$ ). These were based on the information given by Warren et al. that the region covering genes Rv2816 to Rv2819 and portion of Rv2820 is deleted in all Beijing strains of MTB [19]. For multiplex PCR, $10 \mu \mathrm{l}$ master mix was containing $0.1 \mathrm{U}$ of DyNAzyme EXT (Finnzymes Oy, Espoo, Finland), $250 \mu \mathrm{M}$ of each dNTP, $2.0 \mathrm{mM} \mathrm{MgCl} 2,5 \mu \mathrm{M}$ of each primer, and $1 \mu \mathrm{l}(10 \mathrm{ng})$ of template DNA in $1 \times$ EXT buffer. Reaction conditions included $96^{\circ} \mathrm{C}$ for $4 \mathrm{~min}$, followed by 35 cycles of $96^{\circ} \mathrm{C}$ for $45 \mathrm{~s}, 55^{\circ} \mathrm{C}$ for $45 \mathrm{~s}$, and $72{ }^{\circ} \mathrm{C}$ for $1 \mathrm{~min}$, and a final extension at $72^{\circ} \mathrm{C}$ for $5 \mathrm{~min}$. The amplified products were analyzed by electrophoresis on a 3\% agarose gel. Beijing strains of MTB will produce one 523-bp internal control amplified product and one 129-bp product while non-Beijing strains will produce the 523-bp and a104-bp product (Fig. 1).

\section{Statistical analysis}

Results were analyzed with the SPSS software (version 16.0.0) (SPSS Inc., Chicago, IL, USA). The features of the two groups were compared using the Z-test and of three groups by the chi-square $\left(x^{2}\right)$ test, for statistical significance assessment.

\section{Results}

Patients

A total of 381 MTB isolates were isolated. Seventy-six (19.95\%) isolates belong to Beijing genotype among which 45 (11.81\%) were multidrug-resistant. Beijing genotype strains were significantly more common in women $(p=0.01)$ than in men (Table 1$)$.

\section{Strains}

Of the 32 strains that were Beijing genotype as defined by Spoligotyping (total Beijing genotype strains are 76), 30 had all nine characteristic spacers $35-43$, corresponding to the shared type SIT1 as defined in SITVIT2. In the remaining two isolates, one isolate had the last six spacers while another had spacers $37-43$ and spacer 35 correspondings to SIT250 and SIT621 respectively (Table 2).

\section{Drug resistance}

Among 76 Beijing strains, 47 were RIF resistant, 50 were resistant to INH, and 45 were found to be MDR. Thirtyseven strains were resistant to STR and 40 were EMB resistant (Supplementary Table 2). While 50 (65.79\%) and $45(59.21 \%)$ of the Beijing strains were any drugresistant and MDR respectively, 144 (47.21\%) and 76 (24.92\%) of 305 non-Beijing strains were any drugresistant and MDR during the same period representing a statistically significant difference ( $p$-value 0.004 \& 0.032 respectively) (Table 1 ).

\section{Multiplex-PCR}

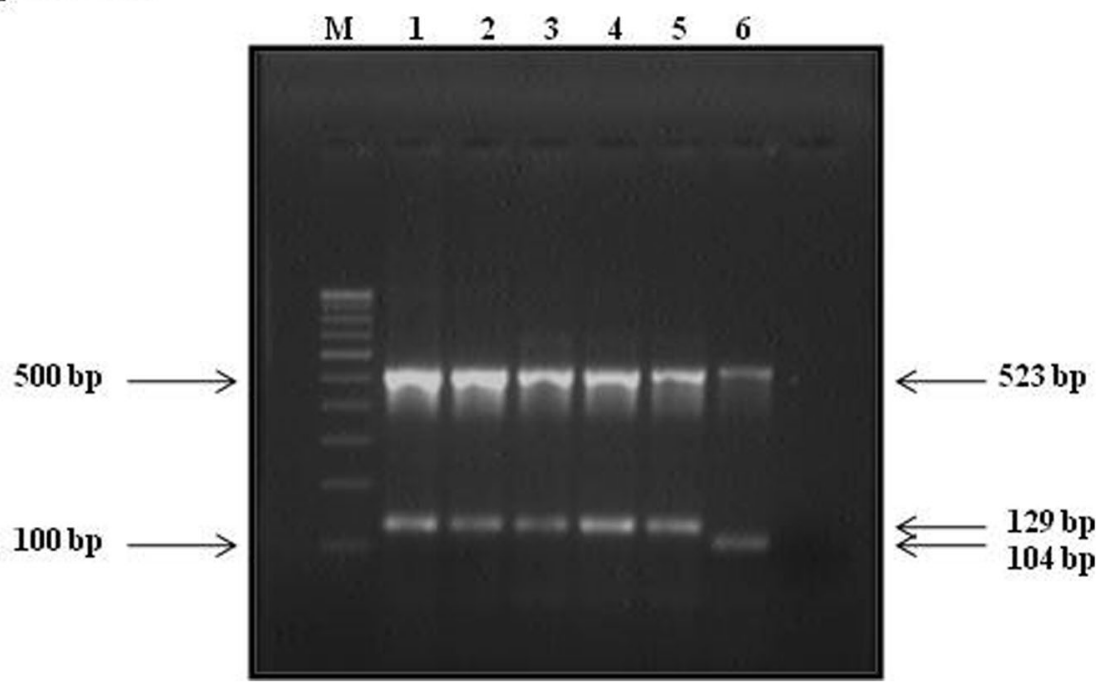

Fig. 1 Agarose gel electrophoresis results of multiplex- PCR products on a 3\% agarose gel: Lanes 1 to 5 showing Beijing strains (129 \& 523 bp fragments); lane 7 showing a non-Beijing strain (104 \& 523 bp fragments); lane M: 100-bp DNA ladder (Bangalore Genei) 
Table 1 Bivariate analysis for selected characteristics in patients with Beijing and non-Beijing genotypes of M.tb of North Central India

\begin{tabular}{|c|c|c|c|c|c|}
\hline Parameters & Beijing genotype, n (\%) & Non- Beijing genotypes, n (\%) & Odds Ratio (OR) & $p$-value* & $95 \% \mathrm{Cl}$ \\
\hline \multicolumn{6}{|l|}{ Sex } \\
\hline Male (250) & $41(53.95)$ & $211(69.18)$ & 0.522 & 0.01 & $0.312-0.871$ \\
\hline Female (131) & $35(46.05)$ & $94(30.82)$ & & & \\
\hline \multicolumn{6}{|l|}{ Age group } \\
\hline$<15(11)$ & $4(5.26)$ & $7(2.3)$ & 2.295 & 0.1 & $0.650-8.106$ \\
\hline 15-44 (290) & $58(76.32)$ & $233(76.39)$ & & & \\
\hline$\geq 45(80)$ & $14(18.42)$ & $65(21.31)$ & 1.155 & 0.6 & $0.606-2.203$ \\
\hline \multicolumn{6}{|l|}{ HIV Status } \\
\hline Sero positive (38) & $8(10.53)$ & $30(9.83)$ & 1.078 & 0.8 & $0.473-2.458$ \\
\hline Sero negative (343) & $68(89.47)$ & $275(90.16)$ & & & \\
\hline \multicolumn{6}{|l|}{ Site of TB } \\
\hline Pulmonary (368) & $73(96.05)$ & $295(96.72)$ & 0.824 & 0.7 & $0.221-3.073$ \\
\hline Extra-pulmonary (13) & $3(3.95)$ & $10(3.28)$ & & & \\
\hline \multicolumn{6}{|l|}{ History of TB } \\
\hline New cases (247) & $39(51.32)$ & $202(66.23)$ & 0.537 & 0.01 & $0.323-0.894$ \\
\hline Previously treated (134) & $37(48.68)$ & $103(33.77)$ & & & \\
\hline \multicolumn{6}{|l|}{ Drug resistance } \\
\hline Any drug resistance (194) & $50(65.79)$ & $144(47.21)$ & 2.15 & & $1.272-$ \\
\hline Susceptible to all $(\mathrm{R}+\mathrm{H}+\mathrm{S}+\mathrm{E})(187)$ & $26(34.21)$ & $161(52.79)$ & & 0.004 & 3.633 \\
\hline MDR (121) & $45(59.21)$ & $76(24.92)$ & 0.586 & 0.032 & $0.359-0.956$ \\
\hline Total Cases (381) & 76 (19.95) & $305(80.05)$ & - & - & - \\
\hline
\end{tabular}

*A $p$ value of $<0.05$ was considered statistically significant

\section{Multiplex-PCR Vs Spoligotyping}

Multiplex PCR was performed for all 381 isolates and spoligotyping was performed in 131 (of 381) isolates. When statistically compared, the results of all 131 isolates were the same for the detection of Beijing and non-Beijing isolates with both the methods. The sensitivities and specificities of multiplex-PCR assay compared to that of standard Spoligotyping was observed to be $100 \%$.

\section{Genotyping for RIF, INH and EMB resistance mutations}

A mutation in katG gene, showing a nucleotide substitution at codon 315 from AGC to ACC, founded in 43/50 $(86 \%)$ of the Beijing strains with phenotypic INH resistance. Resistance mutations at the $r p o B$ gene were found in 45/47 (95.74\%) Beijing strains with phenotypic RIF resistance. A mutation at rpoB codon 531 was most common $(n=29 ; 61.70 \%)$. Of 44 phenotypically EMB resistant isolates, 21 had mutations at $e m b B$ codon 306 (Table 3). Compared to the wild-type (wt) isolates, the isolates with the katG315Thr and rpoB531Leu mutations were most frequent (86 and $61.70 \%$ respectively) in Beijing genotypes (Table 3). Mutations at katG315, rpoB531, and embB306 were more common among Beijing genotype strains, and these associations were observed to be statistically significant $(p=<0.0001,<$ 0.0001 and 0.0014 respectively) (Table 4).

\section{Discussion}

Beijing genotype strain was first isolated in Beijing, China in 1995 and now it has been predominantly found in various parts of the world [20, 21]. A systematic review and meta-analysis on the prevalence of the Beijing genotype strain in world population revealed that its

Table 2 Description of Beijing clades found in this study as determined by spoligotyping ( $n=32,24.43 \%)$

\begin{tabular}{|c|c|c|c|c|}
\hline SIT & Spoligotype Description & Octal Number & Clade & Number (\%) in study \\
\hline 1 & | & 000000000003771 & Beijing & $30(22.90)$ \\
\hline 250 & 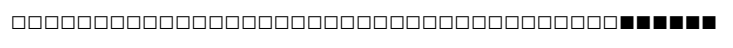 & 000000000000371 & Beijing & $1(0.76)$ \\
\hline 621 & 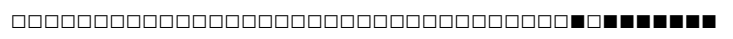 & 000000000002771 & Beijing & $1(0.76)$ \\
\hline
\end{tabular}


Table 3 Drug-resistant Beijing strains of M.tb with different genetic mutation* $(n=76)$

\begin{tabular}{|c|c|c|c|c|}
\hline Gene & $\begin{array}{l}\text { MDR strains, } \\
n=45\end{array}$ & $\begin{array}{l}\text { RIF resistant strains, } \\
n=47\end{array}$ & $\begin{array}{l}\text { INH resistant strains, } \\
n=50\end{array}$ & $\begin{array}{l}\text { EMB resistant strains, } \\
n=44\end{array}$ \\
\hline \multicolumn{5}{|l|}{ katG } \\
\hline 315Thr & 41 & - & 43 & - \\
\hline Others/wt & 4 & - & 7 & - \\
\hline \multicolumn{5}{|l|}{ rpoB } \\
\hline 516Leu or Trp & 3 & 3 & - & - \\
\hline 526Arg,Tyr,Asp,Gly or Asn & 4 & 5 & - & - \\
\hline 531Leu or Trp & 28 & 29 & - & - \\
\hline 526Arg, Tyr.... +531 Leu or trp & 6 & 6 & - & - \\
\hline 516Leu or Trp +531Leu or Trp & 2 & 2 & - & - \\
\hline Others/wt & 2 & 2 & - & - \\
\hline \multicolumn{5}{|l|}{$e m b B$} \\
\hline $306 \mathrm{Val}$ & 13 & - & - & 13 \\
\hline 306lle & 8 & - & - & 8 \\
\hline Others/wt & 24 & - & - & 23 \\
\hline
\end{tabular}

*Mutation detection was done by Multiplex-allele specific-PCR; MDR \#: Resistant to at least INH and RIF with or without resistance to any other anti-tubercular drug. INH isoniazid, RIF rifampicin, STR streptomycin, EMB ethambutol

prevalence was $44.7 \%$ in Asia, $27.9 \%$ in Europe, $12.5 \%$ in Africa, and $8.9 \%$ in America [22]. In India, the Beijing genotype strain is present in a low percentage throughout the country including a previous study in our region [23-25] however we observed a comparatively higher incident rate of the Beijing genotype strain (19.95\%, 76/ 381). Possible reason behind this discrepancy could be the low number of MTB strains studied in the previous study in our region.

We found a 100\% agreement between multiplex-PCR targeting the Rv2820 gene and standard spoligotyping for the detection of Beijing genotype strains of MTB. Similar results were also observed by Sun et al and Sherafat et al [26, 27].

In an extensive review based on the data available from 49 studies in 35 countries on Beijing genotype MTB strain and drug resistance four different patterns of Beijing genotype strains were suggested worldwide but our study population represents a different group; endemic and associated with drug resistance which is now a common pattern for some other countries too $[5,28,29]$.

The worldwide emergence of Beijing genotype strains and their association with multidrug-resistance substantiates the fact that they possess strong capability to acquire drug resistance. This is confirmed by a study, in which 14 drug-resistant clinical isolates of the Beijing genotype were sequenced by whole-genome sequencing to understand the evolution of drug resistance and results showed that the drug resistance among these isolates appeared to be acquired, not clonally derived [30]. Our study observed the similar drift, with 33/50 (66\%) drug resistant-Beijing genotype strains and 29/45 (64.44\%) MDR-Beijing genotype strains from acquired drug-resistant TB patients.

The higher rate of mutations at rpoB531, katG315, and embB306 codons among MTB, Beijing strains provides further evidence that drug resistance may contribute to the global predominance of Beijing genotype strains. In the present study, mutations at codons katG315, rpoB531 and embB306 were more common among Beijing genotype strains than in nonBeijing genotype strains of MTB $(p=<0.0001$; < $0.0001 ; 0.0014$ ) (Table 4). Similar findings were also observed in other studies [6,31-34]. On the basis of our results we consider that recent transmission of Beijing genotype strains could be the driving force of such a high prevalence of the katG315, rpoB531 mutations. Another explanation could be; mutations in

Table 4 Association between M.tb Beijing genotype and drug-resistance gene mutations

\begin{tabular}{lllll}
\hline Gene & Beijing genotype $(\boldsymbol{n}=\mathbf{7 6})$ & Non-Beijing genotypes $(\boldsymbol{n}=\mathbf{3 0 5})$ & OR $(\mathbf{9 5} \% \mathrm{Cl})$-Value $^{*}$ \\
\hline katG315 & $43(56.58 \%)$ & $73(23.93 \%)$ & $4.14(2.45-6.99)$ & $<0.0001$ \\
rpoB531 & $29(38.16 \%)$ & $49(16.07 \%)$ & $3.22(1.85-5.61)$ & $<0.0001$ \\
embB306 & $21(27.63 \%)$ & $38(12.46 \%)$ & $2.68(1.46-4.92)$ & 0.0014 \\
\hline
\end{tabular}

*A $p$ value of $<0.05$ was considered statistically significant 
putative mutator genes have been found in Beijing genotypes, which results in an altered DNA repair and an increased mutation adaptability rate [28].

The strong association of Beijing genotype strain and $k a t G, r p o B$, and $e m b B$ mutations among treated cases of $\mathrm{TB}$, reflects the considerable transmission of MDRBeijing genotype strains in our region which suggests the need of urgent change in the quality of chemotherapy applied in the community.

\section{Conclusions}

In this study, we have successfully evaluated a simple, rapid, robust, and cost-effective multiplex PCR assay for the detection of Beijing genotype of $M$. tuberculosis strains by targeting Rv2820 gene. Study outcomes may provide a scientific basis for the development of new DR-TB diagnostic tools for effective management and control of DR-TB in countries with a higher incidence rate of Beijing genotype strains. Further, a recruitment of large number of representative samples for a systematic study is needed to elucidate the role of Beijing genotype strain in the transmission of $\mathrm{TB}$ and their association with DR-TB in the region. Additional studies using MIRU-VNTRs over an extended period of time can be done to fully understand the epidemiology of TB and its transmission dynamics in our region and all over India.

\section{Supplementary information}

Supplementary information accompanies this paper at https://doi.org/10. 1186/s12879-020-05479-5.

Additional file 1.

Additional file 2.

Additional file 3.

\section{Abbreviations}

MTB: Mycobacterium tuberculosis; DR-TB: Drug-resistant tuberculosis; RRDR: Rifampicin resistance determining region; MDR: Multidrug resistance; RIF: Rifampicin; EMB: Ethambutol; STR: Streptomycin; INH: Isoniazid; PM: Proportion method; BHU: Banaras Hindu University; UP: Uttar-Pradesh

\section{Acknowledgments}

Financial assistance to Dr. Anamika Gupta from the Indian Council of Medical Research is also highly acknowledged.

\section{Authors' contributions}

$A G, P S, V N, P K G, P C, S K, N R$, SA has made substantial contributions to conception and design, or acquisition of data, or analysis and interpretation of data; AG, PS, SA, VN has been involved in drafting the manuscript or revising it critically for important intellectual content; and AG, PS, SA, VN, PKG, PC, SK, NR have given final approval of the version to be published.

\section{Funding}

This study was financially supported by the Indian Council of Medical Research, New Delhi. The funders had no role in study design, data collection, and analysis, decision to publish, or preparation of the manuscript.
Availability of data and materials

The datasets used and analyzed during the current study available from the corresponding author on reasonable request.

Ethics approval and consent to participate

This study has been approved by the ethical committee of the Institute of Medical Sciences, Banaras Hindu University, Varanasi, India.

\section{Consent for publication}

Not applicable.

\section{Competing interests}

The authors declare that they have no competing interests.

\section{Author details}

'Department of Microbiology, Institute of Medical Sciences, Banaras Hindu University, Varanasi 221005 , India. ${ }^{2}$ Division of Molecular Biology, National AIDS Research Institute, 73 G MIDC Bhosari, Pune 411026, India. 'Laboratory Nuclear Medicine Section, Isotope Group, Bhabha Atomic Research Centre C/ o T.M.H. Annexe, Parel, Mumbai 400012, India. ${ }^{4}$ WHO Supranational TB Reference Laboratory, TB \& Mycobacteria Unit, Institute Pasteur de Guadeloupe, Abymes, Guadeloupe, France.

Received: 10 May 2019 Accepted: 5 October 2020

Published online: 14 October 2020

\section{References}

1. Venkataraman P, Paramasivan CN. Drug resistance in tuberculosis and issues related to multidrug resistance in planning for TB control in India. Health Adm Spec Issue Tuberc. 2002;15:127-36.

2. Glynn JR, Whiteley J, Bifani PJ, Kremer K, van Soolingen D. Worldwide occurrence of Beijing $W$ strains of mycobacterium tuberculosis: a systematic review. Emerg Infect Dis. 2002;8:843-9.

3. Tracevska T, Jansone I, Baumanis V, Marga O, Lillebaek T. Prevalence of Beijing genotype in Latvian multidrug-resistant mycobacterium tuberculosis isolates. Int J Tuberc Lung Dis. 2003;7:1097-103.

4. Pang Y, Song Y, Xia H, Zhou Y, Zhao B, Zhao Y. Risk factors and clinical phenotypes of Beijing genotype strains in tuberculosis patients in China. BMC Infect Dis. 2012;12:354.

5. Parwati I, van Crevel R, van Soolingen D. Possible underlying mechanisms for successful emergence of the Mycobacterium tuberculosis Beijing genotype strains. Lancet Infect Dis. 2010;10:103-11.

6. San LL, Aye KS, Oo NAT, Shwe MM, Fukushima Y, Gordon SV, Suzuki Y, Nakajima C. Insight into multidrug-resistant Beijing genotype Mycobacterium tuberculosis isolates in Myanmar. Int J Infect Dis. 2018;76:109-19.

7. Hazbon MH. Bobadilla del Valle M, Guerrero Ml et al. role of embB codon 306 mutations in Mycobacterium tuberculosis revisited: a novel association with broad drug resistance and IS6110 clustering rather than ethambutol resistance. Antimicrob Agents Chemother. 2005;49:3794-802.

8. Gupta A, Singh SK, Anupurba S. Mutations at embB306 codon and their association with multidrug-resistance. tuberculosis clinical isolates. Ind J Med Microbiol. 2015;33:387-92.

9. Arora VK, Gupta R. Dots strategy in India - the challenges. Curr Med J North Zone. 2002; VIII:4.

10. Canetti G, Fox W, Khomenko A, et al. Advances in techniques of testing mycobacterial drug sensitivity, and the use of sensitivity tests in tuberculosis control programs. Bull World Health Organ. 1969:41:21-43.

11. Guidelines for HIV testing. National AIDS control organisation: Ministry of Health and Family Welfare; 2007. http://www.who.int/hiv/pub/guidelines/ india_art.pdf.

12. Van Embden JDA, Cave MD, Crawford JT, et al. Strain identification of Mycobacterium tuberculosis by DNA fingerprinting: recommendations for a standardized methodology. J Clin Microbiol. 1993;1:406-9.

13. Gupta A, Prakash P, Singh SK, et al. Rapid genotypic detection of rpoB and katG gene mutations in Mycobacterium tuberculosis clinical isolates from northern India as determined by MAS-PCR. J Clin Lab Anal. 2013;27:31-7.

14. Mokrousov I, Narvskaya O, Limeschenko E. Detection of ethambutolresistant Mycobacterium tuberculosis strains by multiplex allele-specific PCR assay targeting embB306 mutations. J Clin Microbiol. 2002;40:1617-20. 
15. Kamerbeek J, Schouls L, Kolk A, et al. Simultaneous detection and strain differentiation of Mycobacterium tuberculosis for diagnosis and epidemiology. J Clin Microbiol. 1997;35:907-14.

16. Brudey K, Driscoll JR, Rigouts L, et al. Mycobacterium tuberculosis complex genetic diversity: mining the fourth international spoligotyping database (SpolDB4) for classification, population genetics, and epidemiology. BMC Microbiol. 2006;6:23.

17. Hillemann D, Warren R, Kubica T, et al. Rapid detection of Mycobacterium tuberculosis Beijing genotype strains by real-time PCR. J Clin Microbiol. 2006; 44:302-6.

18. Plikaytis BB, Marden JL, Crawford JT. Multiplex PCR assay specific for the multidrug-resistant strain W of Mycobacterium tuberculosis. J Clin Microbiol. 1994:32:1542-6.

19. Warren RM, Victor TC, Streicher EM, et al. Patients with active tuberculosis often have different strains in the same sputum specimen. Am J Respir Crit Care Med. 2004;169:610-4.

20. Van Soolingen D, Qian L, de Haas PE, Douglas JT, Traore H, Portaels F, et al. Predominance of a single genotype of Mycobacterium tuberculosis in countries of East Asia. J Clin Microbiol. 1995;33:3234-8.

21. Liu Q, Wang D, Martinez L, Lu P, Zhu L, Lu W, Wang J. Mycobacterium tuberculosis Beijing genotype strains and unfavourable treatment outcomes: a systematic review and meta-analysis. Clin Microbiol Infect. 2020;26(2):180-8.

22. Ramazanzadeh $\mathrm{R}$, Sayhemiri K. Prevalence of Beiijing family in Mycobacterium tuberculosis in world population: systematic review and meta-analysis. Inter J Mycobact. 2014;2:109-13.

23. Sharma P, Chauhan DS, Upadhyay P, et al. Molecular typing of Mycobacterium tuberculosis isolates from a rural area of Kanpur by spoligotyping and mycobacterial interspersed repetitive units (MIRUs) typing. Infect Genet Evol. 2008;8:621-6.

24. Stavrum R, Myneedu VP, Arora VK, et al. In-depth molecular characterization of Mycobacterium tuberculosis from New Delhi predominance of drugresistant isolates of the 'modern' (TbD1) type. PLoS One. 2009;4:4540.

25. Mathuria JP, Srivastava GN, Sharma P, Mathuria BL, Ojha S, Katoch VM, Anupurba S. Prevalence of mycobacterium tuberculosis Beijing genotype and its association with drug resistance in North India. J Infect Pub Heal. 2017;10:409-14.

26. Sun JR, Lee SY, Dou HY. Using a multiplex polymerase chain reaction for the identification of Beijing strains of Mycobacterium tuberculosis. Eur J Clin Microbiol Infect Dis. 2009;28:105-7.

27. Sherafat SJ, Goudarzi H, Farnia P. Evaluation of two molecular methods for the detection of Beijing strains of Mycobacterium tuberculosis in pulmonary tuberculosis patients. HealthMED. 2013;7(1):12-6.

28. European Concerted Action on New Generation Genetic Markers and Techniques for the Epidemiology and Control of Tuberculosis. Beijing/W genotype Mycobacterium tuberculosis and drug resistance. Emerg Infect Dis. 2006;12:736-43.

29. Jiao W, Liu Z, Han R, et al. A country-wide study of spoligotype and drug resistance characteristics of Mycobacterium tuberculosis isolates from children in China. PLoS One. 2013;30(8):12-e84315.

30. loerger TR, Feng $Y$, Chen $X$, et al. The non-clonality of drug resistance in Beijing-genotype isolates of Mycobacterium tuberculosis from the Western cape of South Africa. BMC Genomics. 2010;11:670,

31. Lipin MY, Stepanshina VN, Shemyakin IG, et al. Association of specific mutations in katG, rpoB, rpsL, and rrs genes with spoligotypes of multidrugresistant Mycobacterium tuberculosis isolates in Russia. Clin Microbiol Infect. 2007:13:620-6

32. Park YK, Shin S, Ryu S, et al. Comparison of drug resistance genotypes between Beijing and non-Beijing family strains of Mycobacterium tuberculosis in Korea. J Microbiol Methods. 2005;63(2):165-72.

33. Ghebremichael S, Groenheit R, Pennhag A, Koivula T, Andersson E, et al. Drug-resistant mycobacterium tuberculosis of the Beijing genotype does not spread in Sweden. PLoS One. 2010;5(5):e10893. https://doi.org/10.1371/ journal.pone.0010893.

34. Safi H, Sayers B, Hazbón MH. Transfer of embB codon 306 mutations into clinical Mycobacterium tuberculosis strains alters susceptibility to ethambutol, isoniazid, and rifampin. Antimicrob Agents Chemother. 2008;52:2027-34.

\section{Publisher's Note}

Springer Nature remains neutral with regard to jurisdictional claims in published maps and institutional affiliations.

Ready to submit your research? Choose BMC and benefit from:

- fast, convenient online submission

- thorough peer review by experienced researchers in your field

- rapid publication on acceptance

- support for research data, including large and complex data types

- gold Open Access which fosters wider collaboration and increased citations

- maximum visibility for your research: over $100 \mathrm{M}$ website views per year

At BMC, research is always in progress.

Learn more biomedcentral.com/submissions 